\title{
Intermolecular Interactions between Encapsulated Aromatic Compounds and the Host Framework of a Crystalline Sponge
}

\author{
Lilian M. Hayes, ${ }^{\dagger}{ }^{\circledR}$ Neil J. Press, ${ }^{\ddagger}$ Derek A. Tocher, ${ }^{\dagger}$ and Claire J. Carmalt ${ }^{* \dagger}$ \\ ${ }^{\dagger}$ Department of Chemistry, University College London, 20 Gordon Street, London, WC1H 0AJ, U.K. \\ ${ }^{\ddagger}$ Novartis Institutes for BioMedical Research, Basel, Switzerland
}

Supporting Information

ABSTRACT: The crystalline sponge $\left[\left\{\left(\mathrm{ZnI}_{2}\right)_{3}(\right.\right.$ tris $(4$-pyridyl)-1,3,5-triazine $)_{2} \cdot x$ (solvent $\left.\left.)\right\}_{n}\right]$ has been used to produce a range of novel encapsulation compounds with acetophene, trans-cinnamaldehyde, naphthalene, anthracene, and benzylcyanide. Using additional data from previously reported encapsulation compounds, three systematic series have been created and analyzed to investigate the behavior of guest molecules within the sponge framework and identify the dominant intermolecular interactions.

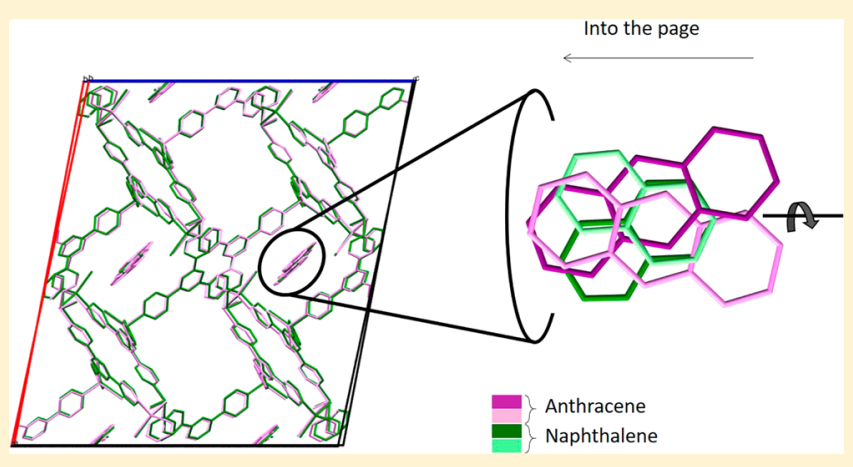

\section{INTRODUCTION}

The crystalline sponge method, first introduced by Fujita et al. in 2013, has garnered attention for its potential to allow the unambiguous structural determination of noncrystalline compounds by single crystal X-ray diffraction (SCXRD). ${ }^{1}$ Through the formation of strong interactions with the crystalline framework of the sponge, noncrystalline compounds otherwise inaccessible to SCXRD may be unambiguously structurally characterized. The method is being applied in an ever increasing variety of experimental situations, from providing mechanistic insight into catalytic processes ${ }^{2,3}$ to the structural elucidation of natural products, ${ }^{4,5}$ ozonides, ${ }^{6}$ metabolites, ${ }^{7}$ and many more. ${ }^{8-10}$

The most successful porous compound used as a crystalline sponge to date is the metal-organic framework (MOF) $\left[\left\{\left(\mathrm{ZnI}_{2}\right)_{3}(\text { tris }(4 \text {-pyridyl })-1,3,5 \text {-triazine })_{2} \cdot(\text { solvent })\right\}_{n}\right]$ (1) developed by Fujita and co-workers, although alternative methods and materials are also being developed. ${ }^{11-15}$ Recently, through the encapsulation of a series of simple organic guests into 1 , we have shown that guest molecules consistently take up specific sites in the unit cell due to specific guest functionality and the nature of the guest-host and guest-guest interactions. ${ }^{16}$ Here, we seek to expand this understanding, and the studies of others, ${ }^{17}$ by presenting work detailing the effect of systematically varying guest size on the interactions formed between guest molecules and the host framework. By these studies we also seek to validate the methodology and expand the scope of the technique by presenting previously unknown encapsulation compounds.

Building on previously published encapsulation complexes of 1 with benzaldehyde $\left(\mathbf{A}^{*}\right)$, benzene $\left(\mathbf{B}^{*}\right)$, and benzonitrile (C*) (Cambridge Crystallographic Database (CSD) refcodes
ULOKEN, ULOLAK, and ULOKAJ respectively), ${ }^{16}$ we set out to create three series of encapsulation complexes with systematic increases in guest size to investigate the effect on preferred positioning within the framework of $\mathbf{1}$ and the most important guest-host interactions. The following compounds were chosen for encapsulation: acetophenone (Ai), transcinnamaldehyde (Aii), naphthalene (Bi), anthracene (Bii), and benzylcyanide (Ci) (Figure 1). Guest molecules and their encapsulation complexes discussed here that have been previously published and are indicated by *.

\section{RESULTS AND DISCUSSION}

Encapsulation Complexes. Encapsulation experiments were performed using either the neat liquid guest (benzaldehyde, acetophenone, trans-cinnamaldehyde, benzene, benzonitrile, and benzylcyanide) or a saturated $\mathrm{CHCl}_{3}$ solution if solid (naphthalene and anthracene). Synthesis of the crystalline sponge followed our preferred literature procedure. ${ }^{18} \mathrm{CHCl}_{3}$ was chosen as the solvent on the grounds of solubility of the solids and the fact that the "as prepared" framework contains labile $\mathrm{CHCl}_{3}$. This resulted in the preparation of encapsulation complexes with acetophenone (1Ai), trans-cinnamaldehyde (1Aii), naphthalene (1Bi), anthracene (1Bii), and benzylcyanide $(\mathbf{1 C i})$. Their unit cell plots are presented in Figure 2, along with those of benzaldehyde $\left(\mathbf{A A}^{*}\right)$, benzene $\left(\mathbf{1 B}^{*}\right)$, and benzonitrile $\left(1 \mathrm{C}^{*}\right)$ generated from CSD entries. Guest molecules are colored according to symmetry equivalence to sites within their own structure and across their individual

Received: November 22, 2016

Revised: December 6, 2016

Published: December 15, 2016 


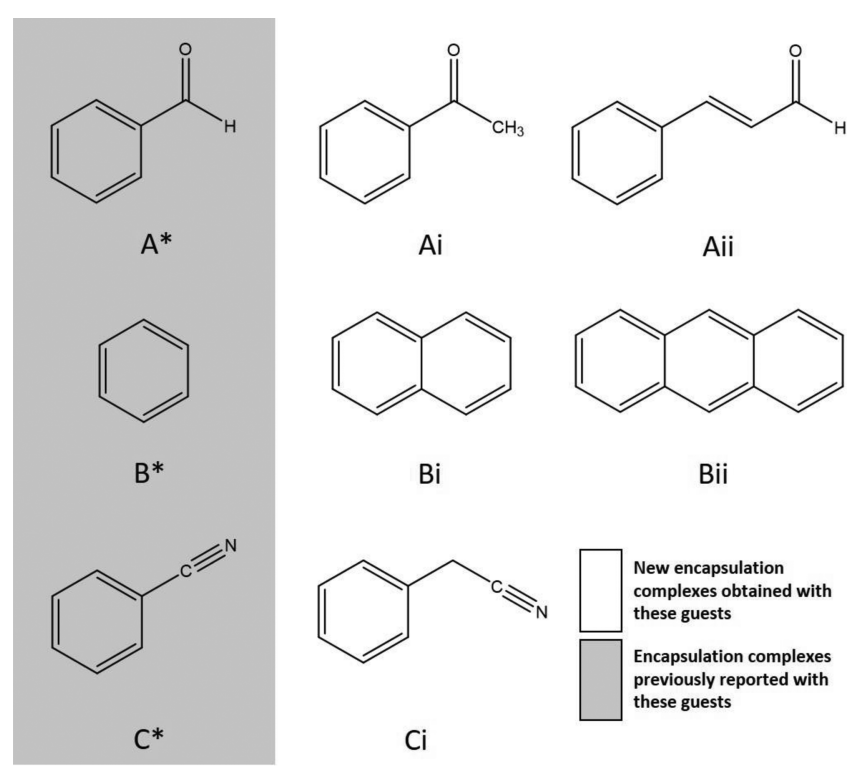

Figure 1. Three systematic series of molecules chosen for encapsulation into (1): Series A: benzaldehyde $\left(A^{*}\right)$, acetophenone (Ai), and trans-cinnamaldehyde (Aii). Series B: benzene $\left(\mathbf{B}^{*}\right)$, naphthalene (Bi), and anthracene (Bii).Series C: benzonitrile $\left(\mathbf{C}^{*}\right)$ and benzylcyanide $(\mathbf{C i})$.

series. Guest molecules were of high occupancy, with site occupancy ranging from 59 to $100 \%$ (see Supporting Information). There are instances of disorder about symmetry positions in $\mathbf{1 A} \mathbf{i}, \mathbf{B} \mathbf{B}$, and $\mathbf{1 C} \mathbf{i}$ and one instance of dynamic disorder in $\mathbf{1 C i}$. In $1 \mathrm{Ci}$, one guest can be identified only by the aromatic ring carbons, and the substituent position is ambiguous (identified by pink coloration of the guest fragment in Figure $2 \mathrm{~h}$ ).

Encapsulation complexes of trans-cinnamaldehyde and anthracene have been previously reported; however, they were synthesized under different experimental conditions resulting in cyclohexane molecules present in the lattice, rather than $\mathrm{CHCl}_{3}$ as used here. As a result, there are differences in the crystal structures obtained with these two guest compounds. The encapsulation complex obtained here with trans-cinnamaldehyde (1Aii) crystallizes in the space group $P \overline{1}$ compared to $\mathrm{C} 2 / \mathrm{c}$ in the literature compounds. ${ }^{1,19}$ The crystal structures also differ in guest uptake, with the previously reported structures containing one guest molecule or two guest molecules per asymmetric unit, while the new structure contains eight. The new structure reported here with anthracene (1Biii) contains one molecule per asymmetric unit, which is more ordered and could be refined anistropically, while only isotropic refinement was reported for the encapsulated guest previously. ${ }^{20}$

Guest Series. An overview of all eight structures shows different guest molecules take up different positions in the unit cell, although some positions are favored and are taken up by guests with a range of functionalities across the series. We have discussed such findings previously ${ }^{16}$ and in this study are interested in the effect of systematically varying the steric requirement in three series of guest molecules and examining the consequences for specific site occupancy and intermolecular interactions.

Series $\boldsymbol{A}$. This series compares the position of guest molecules benzaldehyde $\left(\mathbf{A}^{*}\right)$, acetophenone $(\mathbf{A i})$, and transcinnamaldehyde (Aii). Detailed analysis of the crystal structures shows similar interactions occur in all three complexes resulting in some consistency of positioning in the pore. For example, guest molecules in 1Ai and 1Aii colored yellow in Figure 2a,b are situated in the same site relative to the tris(4-pyridyl)-1,3,5triazine $)_{2}$, TPT linkers, interacting with two pyridyl rings on either side of the pore. This site is also common to the previously reported structure $\mathbf{1 A}^{*}$. The three guests are positioned with only slight rotational differences with respect to the framework (see Figure 3). Each molecule forms four $\mathrm{CH} \cdots \pi$ interactions, the average lengths of which are similar at 3.24, 3.26, and $3.27 \AA$ in $\mathbf{1 A i}$, $\mathbf{1 A i i}$, and $\mathbf{1 A i i i}$ respectively (see Table 1) showing a high degree of consistency regardless of guest size. However, hydrogen bonds $\left(\mathrm{C}=\mathrm{O} \cdots \mathrm{HC}_{\text {pyridyl }}\right)$ are formed by benzaldehyde and acetophenone in these sites (2.41 and $2.63 \AA$ respectively), while the longer chain length in the trans-cinnamaldehyde molecule extends too far into the pore space to allow such a strong interaction. Indeed, the closest atom is a framework iodine at a distance of $3.35 \AA$. This suggests that numerous longer range interactions assist in the ordering of guest molecules, specifically the chains, while the main body of the guest, the aromatic ring, is tethered by multiple strong $\mathrm{CH} \cdots \pi$ interactions. In no instances do we see significantly greater disorder in the chains of the guest molecules compared to their aromatic rings.

Similar interactions were observed between the framework and molecules in a second site (colored blue in Figure 2a,b) albeit with the guest molecules in close enough proximity to form the $\mathrm{CH} \cdots \pi$ interactions with only a single pyridyl ring (Figure 4). The $\mathrm{CH}^{\cdots} \cdots$ centroid distances are comparable to those in the first position. Interestingly, while benzaldehyde and acetophenone molecules sit in this site with a common orientation forming a $\mathrm{C}=\mathrm{O} \cdots \mathrm{HC}_{\text {pyridyl }}$ interaction with the framework (at 2.44 and $2.49 \AA$ respectively), the equivalent trans-cinnamaldehyde molecule is orientated in the opposite direction. This enables it to align with a different pyridyl at an appropriate distance and form a unique $\mathrm{C}=\mathrm{O} \cdots \mathrm{HC}_{\text {pyridyl }}$ hydrogen bond $(2.65 \AA)$.

Series $B$. In this series, all three guest molecules (benzene $\left(\mathbf{B}^{*}\right)$, naphthalene $(\mathbf{B i})$, and anthracene (Bii)) lack functional groups and are ordered in the pores of $\mathbf{1}$ by aromatic interactions alone. Therefore, the guests' steric properties are directly responsible for any changes in positioning and extent of interaction. All three structures contain some residual solvent molecules and vary in the number of guest molecules present in the asymmetric unit. In the case of our previously reported encapsulation complex with benzene $\left(\mathbf{B B}^{*}\right)$ five guest molecules are encapsulated, while in the new compounds there are three of naphthalene and a single anthracene molecule. There is no one site taken up by all three molecules, but there are similarities in the sites observed for the pair of encapsulation complexes naphthalene and anthracene, and also similarities for the benzene and naphthalene pair.

Comparing the structures of $\mathbf{1 B i}$ and $\mathbf{1 B i i}$ we once again see $\mathrm{CH} \cdots \pi$ interactions governing the positioning of some guests, with molecules of naphthalene and anthracene both taking up the site signified by yellow coloration (Figure 2) of the guests, and as described in Series A. Four significant $\mathrm{CH} \cdots$ centroid distances are observed as evidence for this interaction (see Table 1) with slight differences in orientation as shown in Figure 5. Benzene is observed to form similar interactions in $1 \mathrm{~B}^{*}$, albeit at different sites within the unit cell.

Comparing the structure of $\mathbf{1 B i}$ with our previously reported structure $1 \mathbf{B}^{*}$, we can see similarities in position and 

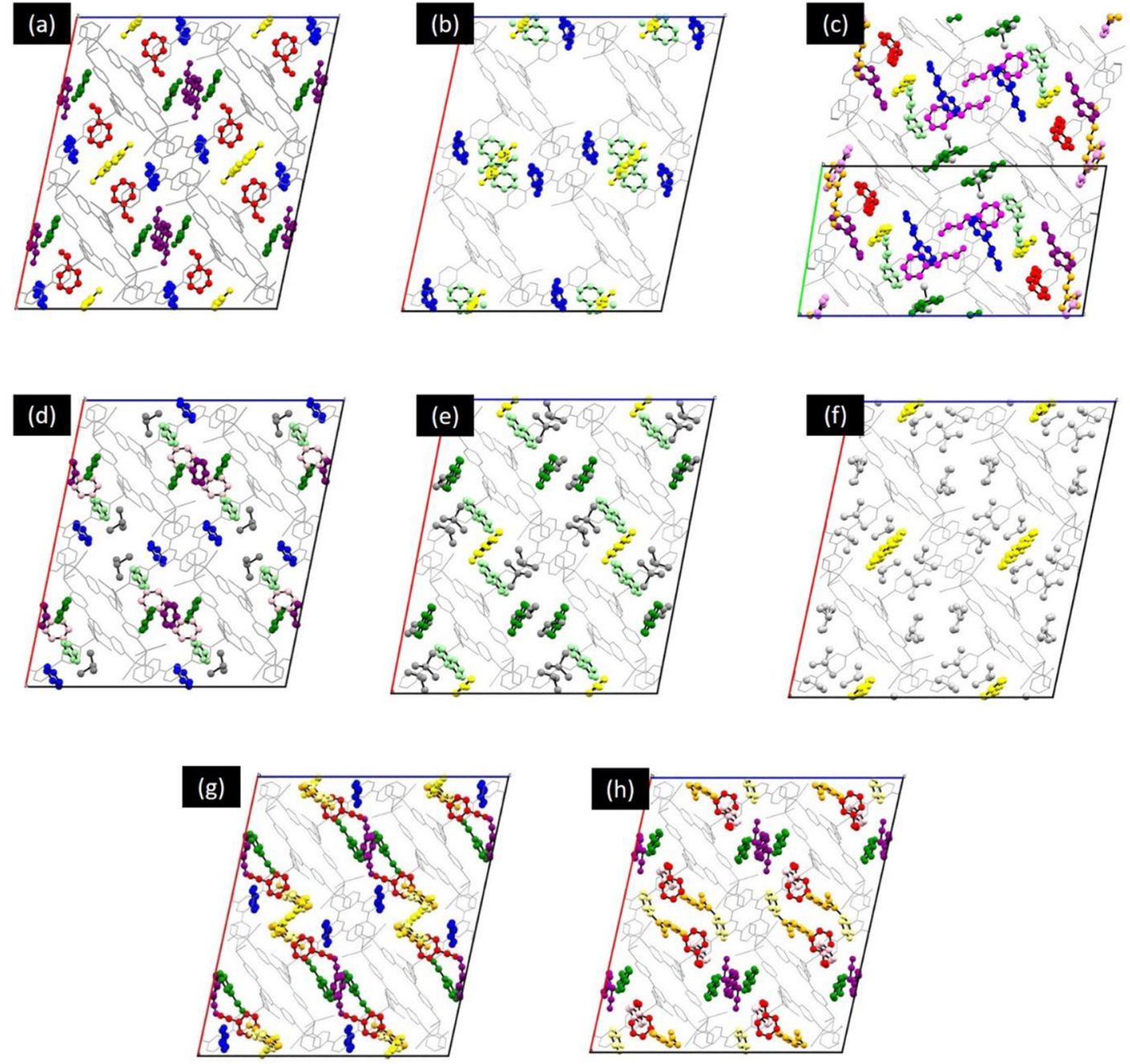

Figure 2. Unit cell plots of the crystal structures, viewed down the $b$ axis [except (c) which is viewed down the $a$-axis for ease of comparison]. (a) Benzaldehyde (1A*), (b) acetophenone (1Ai), (c) cinnamaldehyde (1Aii), (d) benzene (1B*), (e) naphthalene (1Bi), (f) anthracene (1Bii), (g) benzonitrile $\left(\mathbf{1 C}^{*}\right)$, and $(\mathrm{h})$ benzylcyanide $(\mathbf{1 C i i})$. The framework is shown as a gray wireframe and guest molecules as ball and stick models. Hydrogen atoms have been omitted for clarity.

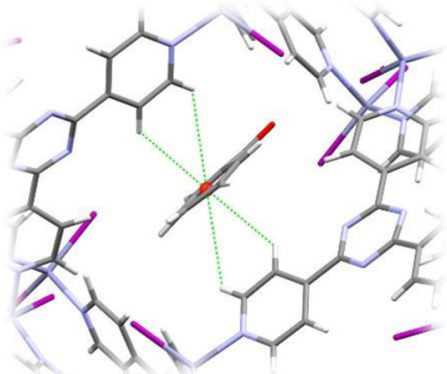

(a)

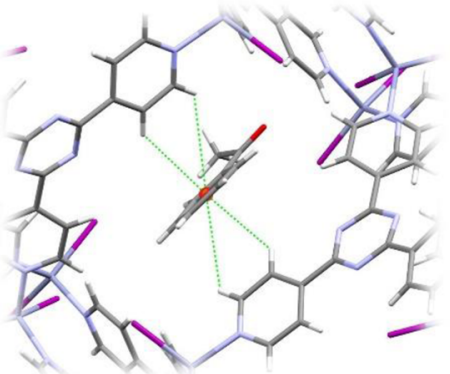

(b)

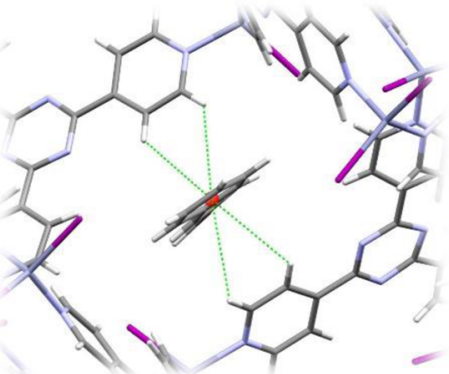

(c)

Figure 3. Guest molecules in the largest cavity of $\mathbf{1}$ (a) benzaldehyde ( $\left.\mathbf{B}^{*}\right)$, (b) acetophenone (Bi), and (c) cinnamaldehyde (Bii). Centroids are shown as red spheres and short contacts as fluorogreen lines.

interactions formed (comparing Figure 2a,b). For example, the naphthalene molecules colored light green are ordered by $\pi \cdots \pi$ interactions formed with a pyridyl group (centroid-centroid distance $3.89 \AA$ ) and a triazide ring (centroid...centroid distance $3.78 \AA$ ). In the analogous part of the unit cell of 1B*, benzene interacts with an adjacent pyridyl ring (centroid $\cdots$ centroid distance $3.59 \AA$ ) of a postionally equivalent
TPT molecule. These contrasting orientations can be seen in Figure 6. We note that the site common to naphthalene and anthracene molecules discussed above is defined by $\mathrm{CH} \cdots \pi$ interactions on both faces of the molecule (Figure 5), contrasting to these light green molecules which sit asymmetrically in the pore, with the framework on the opposite side lying a distant $7 \AA$ away. However, the presence of an additional 
Table 1. CH $\cdots \pi$ Distances between Hydrogens from Pyridyl Groups of the Host Framework and Centroids of the Guests' Aromatic Yellow Rings

\begin{tabular}{lcccccc} 
& & \multicolumn{5}{c}{$\mathrm{CH} \cdots \pi$ interactions $(\AA)$} \\
\cline { 3 - 7 } & guest color & 1 & 2 & 3 & 4 & average \\
$\mathbf{1 A}$ & yellow & 3.03 & 3.46 & 3.04 & 3.43 & 3.24 \\
$\mathbf{1 A i}$ & & 3.07 & 3.55 & 3.01 & 3.41 & 3.26 \\
$\mathbf{1 A i i}$ & & 3.35 & 3.38 & 3.35 & 3.00 & 3.27 \\
$\mathbf{1 A}$ & blue & 3.41 & 3.01 & & & 3.21 \\
$\mathbf{1 A i}$ & & 3.61 & 3.26 & & & 3.44 \\
$\mathbf{1 A i i}$ & & 3.09 & 3.13 & & & 3.11 \\
$\mathbf{1 B i}$ & yellow & 3.26 & 3.41 & 3.00 & 3.28 & 3.24 \\
$\mathbf{1 B i i}$ & & 2.80 & 3.13 & 3.86 & 3.62 & 3.35 \\
\hline
\end{tabular}

benzene guest molecule in $1 \mathrm{~B}^{*}$ (colored blue in Figure 2d) fills the otherwise empty space sitting in close enough proximity to the green site to suggest the presence of a stabilizing intermolecular guest-guest interaction (centroid $\cdots$ centroid distance $4.11 \AA$ ).

Series C. By comparing encapsulation complexes with benzonitrile $\left(\mathbf{1 C}^{*}\right)$ and benzylcyanide $(\mathbf{1 C i})$ we see directly the effect of even a small increase in guest size. Immediately apparent from comparing their unit cell plots (Figure $2 \mathrm{~g}, \mathrm{~h}$ ) is the greater disorder present in the former. Looking at a site within the pore space common to both guests contact measurement suggests the lengthening of the functional group from $\mathbf{C}^{*}$ (benzonitrile) to $\mathbf{C i}$ (benzylcyanide) brings the terminal nitrogen closer in proximity to the framework enabling the formation of stronger stabilizing interactions. For example, guests take up an equivalent position highlighted by orange coloration of guests in Figure $2 \mathrm{~g}$,h. Both guests are disordered over two orientations, although the nature of the disorder is different. In the case of benzonitrile the rings are rotationally offset at an angle of about $22.63^{\circ}$ between the two positions (Figure 7a). In comparison, the $\mathrm{CH}_{2} \mathrm{CN}$ group of benzylcyanide sits on a pseudo axis about which the molecule is disordered, with the phenyl rings rotated $138.25^{\circ}$ relative to one another (Figure $7 \mathrm{~b}$ ). The disorder parts are highlighted by cream coloration in Figure $2 \mathrm{~g}, \mathrm{~h}$.

Contact measurements show all positions are anchored by similar interactions between the guest aromatic ring and pyridyl of the framework. However, a shorter $\mathrm{CN} \cdots \mathrm{H}_{\text {pyridiyl }}$ interaction is observed with benzylcyanide at $2.72 \AA$, the only crystallographically well-ordered part of the guest. In the case of benzonitrile, the two disordered components make contacts of

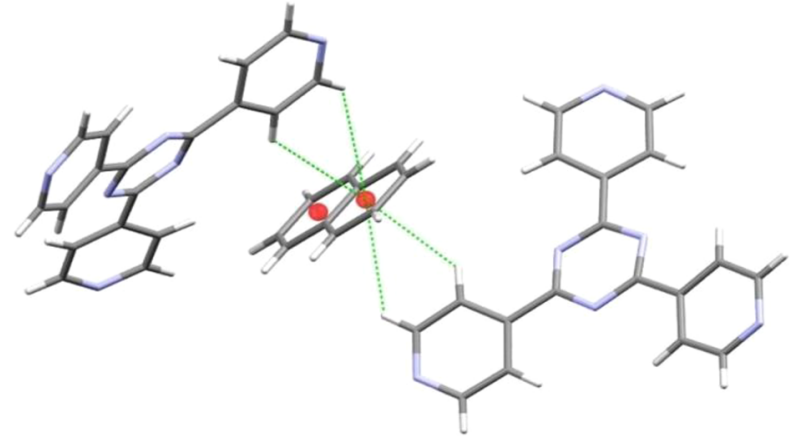

(a)

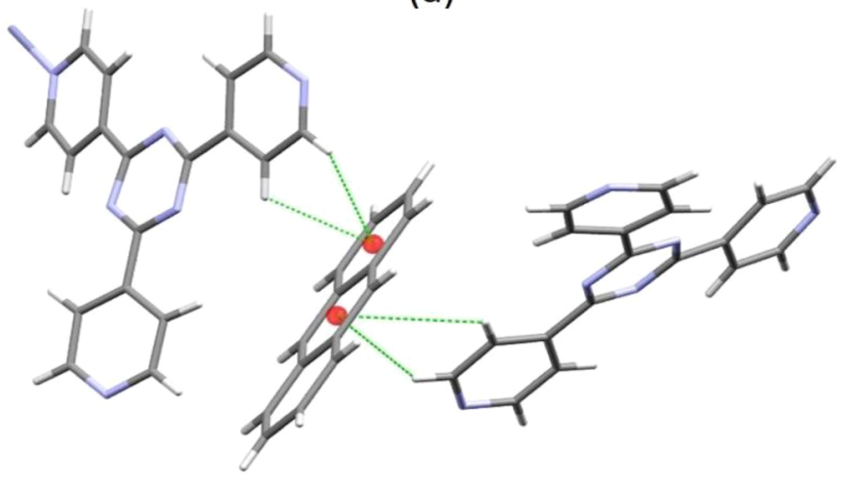

(b)

Figure 5. A comparison of the $\mathrm{CH} \cdots \pi$ interaction between the framework and (a) naphthalene $(\mathbf{1 B i})$ or (b) anthracene (1Bii) at equivalent sites within their respective unit cells. Centroids are shown as red spheres and short contacts as fluorogreen lines.

3.18 and $2.92 \AA$. This suggests differences in guest size can affect disorder by strengthening or weakening the interaction with the crystalline sponge framework, with an interplay between aromatic interaction and those associated directly with the functional group.

\section{CONCLUSION}

We have reported five new encapsulation compounds, including three with guests not previously observed inside the crystalline sponge $\left[\left\{\left(\mathrm{ZnI}_{2}\right)_{3}(\text { tris }(4 \text {-pyridyl })-1,3,5 \text {-triazine })_{2}\right.\right.$. $\left.\left.x\left(\mathrm{CHCl}_{3}\right)\right\}_{n}\right]$. As such the methodology is validated and the scope of the technique is expanded. Measurement of intermolecular interactions in relation to guest size and functionality shows the consistency with which $\mathrm{CH} \cdots \pi$ and

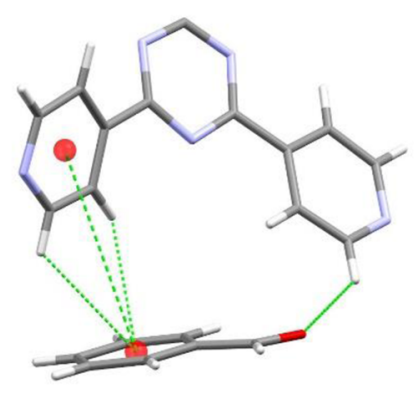

(a)

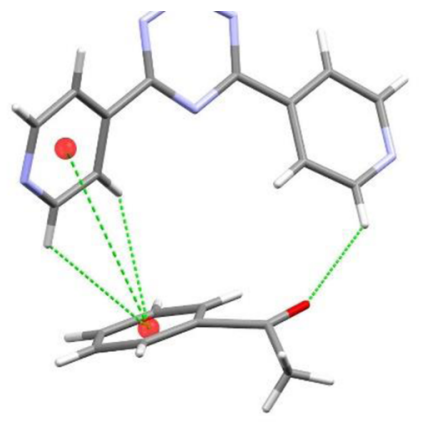

(b)

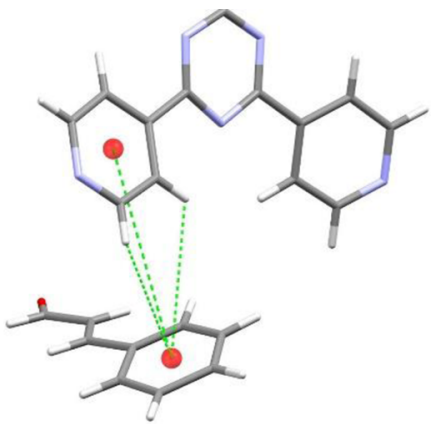

(c)

Figure 4. Guest molecules of (a) benzaldehyde, (b) acetophenone, (c) cinnamaldehyde interacting with framework tris(4-pyridyl)-1,3,5-triazine at analogous positions within the crystalline sponge. Centroids are shown as red spheres and short contacts as fluorogreen. 


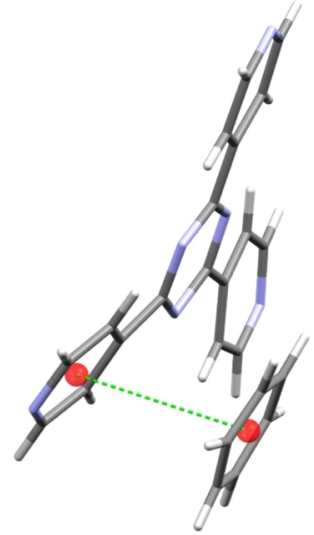

(a)

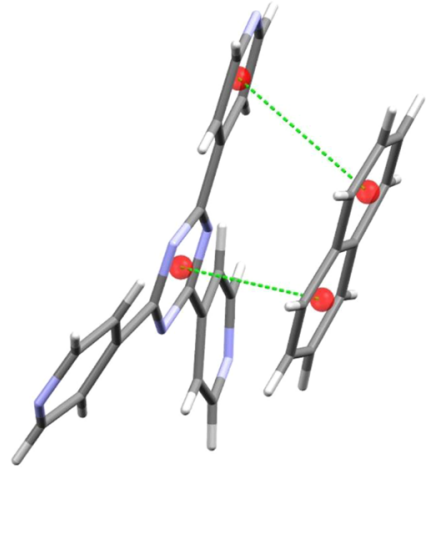

(b)
Figure 6. A comparison of the $\pi \cdots \pi$ interaction formed by a TPT linker in the framework of $\mathbf{1}$ with (a) benzene $\left(\mathbf{B}^{*}\right)$ and (b) naphthalene $(\mathbf{B i})$ at equivalent sites. Centroids are shown as red spheres and intercentroid contacts as fluorogreen lines.

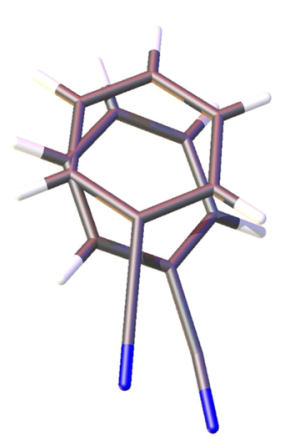

(a)

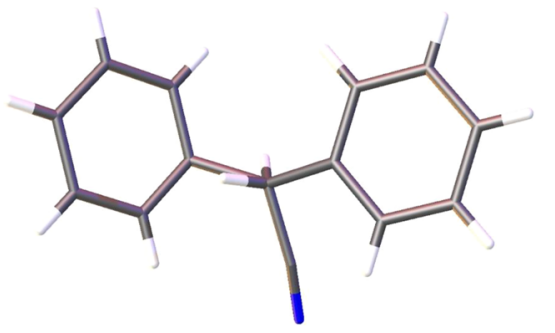

(b)
Figure 7. Disorder observed in the positioning of (a) benzonitrile $\left(\mathbf{1 C}^{*}\right),(\mathrm{b})$ benzylcyanide $(\mathbf{1 C i})$ molecules at a specific site in the pore of 1 .

$\pi \cdots \pi$ interactions are formed and their importance in determining the location of the guest molecules within the pore structure. Because of the aromaticity of all guest molecules, many of those reported here take up similar positions within the unit cell, but small changes in the functionality and size of guest molecules may affect their orientation and ordering within the sponge framework.

\section{EXPERIMENTAL SECTION}

Crystalline Sponge Synthesis and Guest Encapsulation. $\left[\left\{\left(\mathrm{ZnI}_{2}\right)_{3}\left(\text { tris }(4 \text {-pyridyl)-1,3,5-triazine })_{2} \cdot x\left(\mathrm{CHCl}_{3}\right)\right\}_{n}\right]\right.$ was prepared following the procedure reported in the literature. ${ }^{18}$ For guest encapsulation, the mother liquor was reduced to the minimum volume while still covering the crystals, and the neat guest liquid (liquid guests $\mathbf{A i}, \mathbf{A i i}$, and $\mathbf{C i}$ ) or saturated solution (solid guests $\mathbf{B i}$ and Bii) $\left(\sim 1 \mathrm{~cm}^{3}\right)$ was pipetted in. After a specific number of days (3-7; see Supporting Information) of incubation at $\sim 22^{\circ} \mathrm{C}$, suitable rod- or block-shaped crystals were selected and subjected to SCXRD.

Crystallographic Procedures. Crystals were placed in Fomblin, and single crystals were selected and mounted onto nylon loops. X-ray diffraction data were recorded on an Agilent Super Nova dual diffractometer (Agilent Technologies Inc., Santa Clara, CA) with $\mathrm{Cu}$ $\mathrm{K} \alpha$ radiation $(\lambda=1.5418 \AA)$ at $150 \mathrm{~K}$. Unit cell determination, data reduction, and absorption corrections were carried out using CrysAlisPro. ${ }^{21}$ The structures were solved with the Sir $2004^{22}$ structure solution program by direct methods or Superflip ${ }^{23}$ and refined by full- matrix least-squares on the basis of $\mathrm{F}^{2}$ using SHELX $2013^{24}$ within the $\mathrm{OLEX}^{25}$ graphical user interface. Non-hydrogen atoms were refined anisotropically, and hydrogen atoms were included using a riding model. Details of the treatment of individual guest molecules can be found in the Supporting Information.

\section{ASSOCIATED CONTENT}

\section{S Supporting Information}

The Supporting Information is available free of charge on the ACS Publications website at DOI: 10.1021/acs.cgd.6b01694.

Crystal data and guest occupancy details and encapsulation conditions (PDF)

\section{Accession Codes}

CCDC 1517773 and 1517775-1517778 contain the supplementary crystallographic data for this paper. These data can be obtained free of charge via www.ccdc.cam.ac.uk/data_request/ cif, or by emailing data_request@ccdc.cam.ac.uk, or by contacting The Cambridge Crystallographic Data Centre, 12 Union Road, Cambridge CB2 1EZ, UK; fax: +44 1223336033.

\section{AUTHOR INFORMATION}

\section{Corresponding Author}

*E-mail: c.j.carmalt@ucl.ac.uk. Tel: +44 (0)20 7679 7528. Fax: +44 (0)207679 7463 .

\section{ORCID}

Lilian M. Hayes: 0000-0002-0033-6132

\section{Notes}

The authors declare no competing financial interest.

\section{ACKNOWLEDGMENTS}

The authors would like to thank the BBSRC (BB/L016265/r) and Novartis for research funding.

\section{REFERENCES}

(1) Inokuma, Y.; Yoshioka, S.; Ariyoshi, J.; Arai, T.; Hitora, Y.; Takada, K.; Matsunaga, S.; Rissanen, K.; Fujita, M. Nature 2013, 495 (7442), 461-466.

(2) Ikemoto, K.; Inokuma, Y.; Rissanen, K.; Fujita, M. J. Am. Chem. Soc. 2014, 136 (19), 6892-6895.

(3) O'Brien, A. G.; Maruyama, A.; Inokuma, Y.; Fujita, M.; Baran, P. S.; Blackmond, D. G. Angew. Chem., Int. Ed. 2014, 53 (44), 1186811871.

(4) Lee, S.; Hoshino, M.; Fujita, M.; Urban, S. Chem. Sci. 2017, DOI: $10.1039 /$ C6SC04288K.

(5) Urban, S.; Brkljača, R.; Hoshino, M.; Lee, S.; Fujita, M. Angew. Chem., Int. Ed. 2016, 55 (8), 2678-2682.

(6) Yoshioka, S.; Inokuma, Y.; Duplan, V.; Dubey, R.; Fujita, M. J. Am. Chem. Soc. 2016, 138, 10140.

(7) Inokuma, Y.; Ukegawa, T.; Hoshino, M.; Fujita, M. Chem. Sci. 2016, 7, 3910-3.

(8) Matsuda, Y.; Mitsuhashi, T.; Lee, S.; Hoshino, M.; Mori, T.; Okada, M.; Zhang, H.; Hayashi, F.; Fujita, M.; Abe, I. Angew. Chem., Int. Ed. 2016, 55 (19), 5785-5788.

(9) Takizawa, S.; Kishi, K.; Yoshida, Y.; Mader, S.; Arteaga, F. A.; Lee, S.; Hoshino, M.; Rueping, M.; Fujita, M.; Sasai, H. Angew. Chem. 2015, 127, 15731-15735.

(10) Zigon, N.; Hoshino, M.; Yoshioka, S.; Inokuma, Y.; Fujita, M. Angew. Chem., Int. Ed. 2015, 54, 9033-9037.

(11) Ramadhar, T. R; Zheng, S.-L.; Chen, Y.-S.; Clardy, J. Chem. Commun. 2015, 51 (56), 11252-11255.

(12) Zhang, S.-Y.; Wojtas, L.; Zaworotko, M. J. J. Am. Chem. Soc. 2015, 137 (37), 12045-12049. 
(13) Sanna, E.; Escudero-Adán, E. C.; Bauzá, A.; Ballester, P.; Frontera, A.; Rotger, C.; Costa, A. Chem. Sci. 2015, 6 (10), 54665472.

(14) Ning, G.-H.; Matsumura, K.; Inokuma, Y.; Fujita, M. Chem. Commun. 2016, 52, 7013-7015.

(15) Lee, S.; Kapustin, E. A.; Yaghi, O. M. Science (Washington, DC, U. S.) 2016, 353 (6301), 808-811.

(16) Hayes, L. M.; Knapp, C. E.; Nathoo, K. Y.; Press, N. J.; Tocher,

D. A.; Carmalt, C. J. Cryst. Growth Des. 2016, 16 (6), 3465-3472.

(17) Brunet, G.; Safin, D. A.; Korobkov, I.; Cognigni, A.; Murugesu, M. Cryst. Growth Des. 2016, 16, 4043-4050.

(18) Ramadhar, T. R.; Zheng, S.; Chen, Y.; Clardy, J. Acta Crystallogr., Sect. A: Found. Adv. 2015, 71 (1), 46-58.

(19) Hoshino, M.; Khutia, A.; Xing, H.; Inokuma, Y.; Fujita, M. IUCrJ 2016, 3 (2), 139-151.

(20) Ohmori, O.; Kawano, M.; Fujita, M. J. Am. Chem. Soc. 2004, 126 (50), 16292-16293.

(21) CrysAlisPro: Yarnton, England, 2015.

(22) Caliandro, R.; Carrozzini, B.; Cascarano, G. L.; Giacovazzo, C.; Mazzone, A.; Siliqi, D. J. Appl. Crystallogr. 2009, 42 (2), 302-307.

(23) Palatinus, L.; Chapuis, G. J. Appl. Crystallogr. 2007, 40 (4), 786790.

(24) Sheldrick, G. M. Acta Crystallogr., Sect. C: Struct. Chem. 2015, 71 (Md), 3-8.

(25) Dolomanov, O. V.; Bourhis, L. J.; Gildea, R. J.; Howard, J. a K.; Puschmann, H. J. Appl. Crystallogr. 2009, 42 (2), 339-341. 